\title{
CONFESIÓN ESPONTÁNEA EN EL EMPLAZAMIENTO EN MATERIA CIVIL
}

\author{
SPONTANEOUS CONFESSION AT THE CIVIL MATTER SITE
}

\author{
Ivette Delfina Rodríguez-García ${ }^{1}$ (iD
}

1. Escuela Judicial del Poder Judicial del Estado de Tabasco, México. vetita83@hotmail.com

* Autor de correspondencia: Ivette Delfina Rodríguez-García, correo electrónico: vetita83@hotmail.com

\section{RESUMEN}

En materia civil hay que considerar la prueba como acción de evidenciar un derecho o hecho de acuerdo a los medios establecidos, es demostrar la verdad o falsedad, la cual se equipara a la existencia o inexistencia de algo. En ese sentido, la confesión espontánea en el emplazamiento, aborda de manera deductiva una descripción de precepto legal dentro del marco doctrinal y normativo que existe al respecto a través, de un proceso teórico metodológico que detalla los elementos de emplazamiento, prueba y confesión.

Palabras clave: confesión; juicio; medios de prueba.

Cómo citar:

Rodríguez-García, Ivette Delfina. (2021). Confesión espontánea en el emplazamiento en materia civil. Revista de Investigaciones Universidad del Quindío, 33(S2), 18-23. https://doi.org/10.33975/ riuq.vol33nS2.606 


\begin{abstract}
In civil matters, proof must be considered as an action to demonstrate a right or fact according to the established means, it is to demonstrate the truth or falsehood, which is equated to the existence or nonexistence of something. In this sense, the spontaneous confession at the site, deductively addresses a description of the legal precept within the doctrinal and normative framework that exists in this regard through a theoretical methodological process that details the elements of location, evidence and confession.
\end{abstract}

Keywords: confession; trial; evidence.

\title{
INTRODUCCIÓN
}

En este artículo se analizará los preceptos legales del Código de Procedimientos Civiles en vigor de Tabasco, que reglamenta la diligencia de emplazamiento; siendo los numerales 134, 213 y 214; los cuales tratan de la forma en que debe realizarse el emplazamiento así como los efectos jurídicos de ésta diligencia; pero en ninguna de sus partes se reglamenta que se deba preguntar al demandado sí reconoce o no el documento base de la acción con el que se le corre traslado y si reconoce o no las prestaciones reclamadas. En ese sentido y para la búsqueda de la verdad (García, 2008) se propone que debe ser obligación del actuario o actuaria judicial que al practicar la diligencia de emplazamiento directamente con el demandado, le pregunte si reconoce el documento base de la acción y si acepta o no las prestaciones reclamadas por el demandante; a efectos que al resolverse el fondo del asunto en un momento dado se pueda tomar en cuenta la confesión espontánea de la parte demanda en la diligencia de emplazamiento.

Porque es la primera actuación por parte del órgano jurisdiccional donde interviene directamente la parte demanda. Además, porque precisamente a la diligencia de emplazamiento se le ha reconocido como un acto judicial de gran trascendencia porque garantizar el acceso a la justicia del demandado para que éste pueda ser oído y vencido en juicio; pero también se le debe de dotar de eficacia para alcanzar la búsqueda de la verdad de los hechos planteados.

\section{METODOLOGÍA}

Dado el apremio de identificar y estudiar elemento del derecho civil conforme a la normativa existente en el marco regulador federal y local. Está investigación es de alcance cualitativo con enfoque documental, descriptivo y exegético. Se expone de forma deductiva el emplazamiento, la prueba y la confesión planteando el alcance y aplicación de los mismos.

\section{RESULTADOS}

\section{El emplazamiento}

Ovalle Favela describe el emplazar como "conceder un plazo para la realización de determinada actividad procesal el cual es ejecutado por el notificador o actuario, en virtud del cual el juzgador hace del conocimiento del demandado la existencia de una demanda en su contra y del auto que la admitió, y le concede un plazo para que la conteste." (Ovalle, 2012). Asimismo, distingue el emplazamiento mediante dos elementos: 
1. Notificación. Se notifica al demandado que existe una demanda hacia su persona, la cual ha sido aceptada por el juez.

2. Emplazamiento. Concede al demandado un plazo para dar contestación a la demanda.

Gómez Lara (2004) describe el emplazamiento como "el acto formal en virtud del cual se hace saber al demandado la existencia de la demanda entablada en su contra por el actor y la resolución del juez que, al admitirla establece un término (plazo) dentro del cual el reo debe comparecer a contestar el libelo correspondiente"

El Código Federal de Procedimientos Civiles (1943) en el capítulo II denominado Emplazamiento, dispone en el artículo 327

"De la demanda admitida se correrá traslado a la persona contra quien se proponga, emplazándola para que la conteste dentro de nueve días, aumentados con los que correspondan por razón de la distancia".

En su Artículo 328 dispone que "los efectos del emplazamiento son: prevención del juicio a favor del tribunal que lo realiza, sujetar al emplazado continuar ente el tribunal que lo emplazó, salvo el derecho de promover la incompetencia, producir las consecuencias de interpelación judicial.”

En ese tenor, el Código de Procedimientos Civiles para el estado de Tabasco (1997) en su artículo 134 dispone:

"Cuando se trate del emplazamiento, el actuario, además de la cédula a que se refiere el artículo anterior, entregará a la persona con quien entienda la diligencia, copia simple o fotostática de la demanda debidamente cotejada y sellada, más, en su caso, de los demás documentos exhibidos por el actor con su escrito inicial. Si después de que el actuario se hubiere cerciorado de que la persona por notificar vive en la casa y la persona con quien se entienda la diligencia se negare a recibir el emplazamiento, éste se hará en el lugar donde el demandado trabaje habitualmente o tenga el principal asiento de sus negocios, sin necesidad de que el juzgador dicte una determinación especial para tal fin. En este supuesto, el actuario deberá expresar en el acta los medios por los cuales se cercioró de que el lugar donde practicó la diligencia, es donde el demandado trabaja habitualmente o tiene el principal asiento de sus negocios."

Se señala que dicho acto se debe de realizar a la persona(s) contra quienes se promueve la demanda, teniendo como plazo un periodo de nueve días para la contestación.

Los efectos del emplazamiento conforme al Artículo 214 son:

I.- Constituir relación jurídica procesal;

II.- Imponer al demandado la carga de contestar la demanda ante el órgano jurisdiccional que lo emplazó, salvo siempre el derecho de impugnar la competencia;

III.- Producir todas las consecuencias de la interpelación judicial, si por otras causas no se hubiere constituido en mora el obligado;

IV.- Determinar que el poseedor, aunque sea de buena fe, no adquiera los frutos percibidos, quedando éstos a las resultas del juicio; y

V.- Dar lugar a que el contrato cuyo objeto sea la enajenación de los derechos o bien litigioso, se pueda nulificar, si se hubiere celebrado sin conocimiento y aprobación del juzgador o de las partes litigantes. 


\section{La prueba}

De acuerdo a Ovalle Favela (s.f.) se puede considerar la prueba procesal en sentido estricto y amplio, el primero referido a que la prueba es la obtención del cercioramiento jurisdiccional de los hechos para la solución de la controversia sometida a proceso. La segunda responde a comprender todas las actividades procesales realizadas para la obtención del cercioramiento, más allá de que se obtenga o no.

Al respecto, Gómez (2004), refiere que en cuanto a la prueba no son los hechos, sino las afirmaciones que de los mismos hacen las partes, las que deben probarse.

El Código Federal de Procedimiento Civiles, establece en el Artículo 79:

"Para conocer la verdad, puede el juzgador valerse de cualquier persona, sea parte o tercero, y de cualquier cosa o documento, y a sea que pertenezca a las partes o a un tercero, sin más limitaciones que las de que las pruebas estén reconocidas por la ley y tengan relación inmediata con los hechos controvertidos. Los tribunales no tienen límites temporales para ordenar la aportación de las pruebas que juzguen indispensables para formar su convicción respecto del contenido de la litis, ni rigen para ellos las limitaciones y prohibiciones, en materia de prueba, establecidas en relación con las partes".

Lo que implica agotar las pruebas (Devis, s.f.) en valor de la verdad para cada una de las partes durante el juicio.

El Código de Procedimientos Civiles para el estado de Tabasco en el artículo 243, señala como medios de prueba la confesión, declaración de las partes, documentos públicos y privados, dictámenes periciales, inspección judicial, testimonios, fotografías, copias fotostáticas (medios audiovisuales), informe de autoridades. Estos medios son conforme las partes consideran convenientes para la declaración de hechos en el que sean instituidas sus acciones y excepciones.

\section{La confesión}

Ovalle Favela describe que la confesión se ha visto reducida en su estimación, en el proceso civil tiende a ser sustituida por la simple declaración de parte libremente apreciada por el juez.

Describe la confesión judicial espontánea o provocada como "la primera es aquella que una parte formula, ya en su demanda o en su contestación, sin que su contraparte haya requerido la prueba; y la confesión judicial provocada es la que se realiza cuando una de las partes ofrece la prueba de confesión de su contraparte y se practica cumpliendo las formalidades legales." (Ovalle, 2012, p.148). El autor señala una diferencia en los criterios, la primera a voluntad de una de las partes y la segunda respecto a una obligación requerida.

Este tipo de confesión supone en el aspecto de interrogatorio directo o reciproco (Perla, s.f.), oculto hasta el momento de la audiencia. Ya que la parte que declara lo realiza hasta el momento del juicio en presencia del juez.

Couture (1958) define la confesión como "acto jurídico consistente en consentir como cierto, expresa o tácitamente, dentro o fuera del juicio, un hecho cuyas consecuencias de derecho son perjudiciales 
para aquel que formula la declaración” señala asumir la responsabilidad de actos realizados.

Verdugo (2010) describe la confesión espontánea (no forzada) como aquella declaración de hechos desfavorables a la parte referidos en el escrito de demanda o contestación. Señala el acto de voluntad en la declaración por parte de la persona.

Pérez \& Núñez (2010) distinguen la confesión espontánea como aquella que realizan las partes en el juicio mediante los escritos, en el que las partes no pueden retractarse consecuentemente de realizarla. Lo que infiere que es un acto irrevocable que atañe asumir la responsabilidad de la acción de forma voluntaria ante la autoridad.

Conforme a lo Dispuesto en el Código Federal de Procedimientos Civiles en el artículo 95 se entiende que "la confesión puede ser expresa o tácita: expresa, la que se hace clara y distintamente, ya al formular o contestar la demanda, ya absolviendo posiciones, o en cualquier otro acto del proceso; tácita, la que se presume en los casos señalados por la ley.”

Al respecto, el Código de Procedimientos Civiles para el estado de Tabasco, en su Artículo 250, describe que el periodo en que debe ofrecerse la confesión es hasta diez días previo a la audiencia de pruebas. Existe entonces un periodo para estructurarlas y presentarlas en audiencia.

Como bien se señala la prueba confesional es un acto de declaración de una de las partes involucradas en la Litis, en el que reconoce y asume un hecho que le perjudica; se consuma el acto espontáneo al momento que la persona declara respecto y sobre hechos propios, en el que se considera que su declaración no fue manipulada, debido a que hasta ese momento son desconocidas para la persona que comparece al desahogo de la probanza.

\section{CONCLUSIÓN}

La confesión es una declaración vinculativa la cual conlleva considerar el reconocer y asumir hechos de consecuencia jurídica. Llevar a efecto una confesión espontánea referida como aquella que surgen por iniciativa del confesante puede ser considerada como testimonio de parte, debe señalarse que no debe incurrir en un esquema de trampas e interpretaciones con sentido, alcance y configuradas fuera del margen de la lealtad procesal.

\section{REFERENCIAS}

1. Devis Echandia, Hernando. (s.f.). Teoría general de la prueba judicial. Victor P. de Zavala: Buenos Aires.

2. Couture. (1958). Fundamentos del derecho procesal civil. Depalma: Buenos Aires.

3. Diario Oficial de la Federación. (1943). Código de Federal de Procedimientos Civiles. México. Última reforma publicada DOF 09-04-2012.

4. García Rojas, Gabriel. (2008). Derecho procesal civil. Suprema Corte de Justicia de la Nación, Benemérita Universidad Autónoma de Puebla: México.

5. Gómez Lara, Cipriano. (2004) Teoría general del proceso. OXFORD: México.

6. Marín Verdugo, Felipe (2010). Declaración de la parte como medio de prueba. Ius et Praxis, 16(1),125-170.

7. Ovalle Favela, José. (2012). Derecho procesal civil. OXFORD: México. 
8. Ovalle Favela, José. (s.f.). La teoría general de la prueba. México.

9. Pérez Ragone, Álvaro, Nuñez Ojeda, Raúl. (2013). Manual de derecho procesal civil. Parte general. LegalPublishing: Chile.

10. Periódico Oficial del Gobierno del estado de Tabasco. (1997). Código de Procedimientos Civiles para el estado de Tabasco. Última reforma publicada 16-10-2019.

11. Perla Velaochaga, Ernesto. (s.f.). Temas de derecho procesal. Colombia. 